\title{
Do employees participate in workplace HIV testing just to win a lottery prize? A quantitative study
}

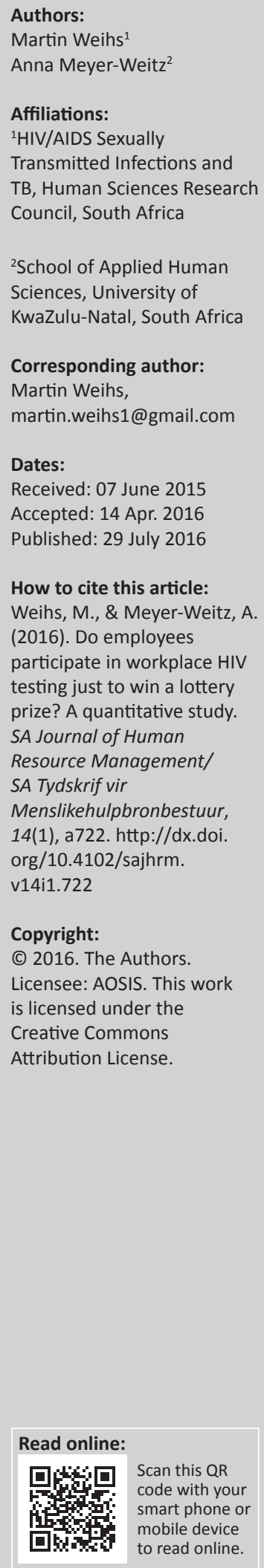

Orientation: To encourage workers to participate in workplace HIV testing, some South African automotive companies use lotteries. However, there is a lack of empirical evidence on how lottery incentives may influence employees' workplace HIV counselling and testing behaviour.

Research purpose: Determine whether workers intend to test for HIV only to win a lottery prize.

Motivation for the study: The positive and also negative influences of lotteries on workers' HIV testing behaviour need to be understood to avoid undue coercion in workplace HIV testing participation.

Research design, approach and method: Post-test only quasi-experimental studies were conducted the day HIV testing and lotteries were announced to staff in four companies using a cross-sectional, self-administered survey that measured workers' workplace HIV testing behaviour intentions. Intention to participate in workplace HIV counselling and testing was used as the main outcome of respondents' behaviour and investigated via the statement: 'If the company would organise its on-site Wellness Day tomorrow, I would go testing for HIV tomorrow'. In a first setting, two companies' workers had to test for HIV to be entered in the lottery $(n=198)$. In the second setting, two other companies' workers did not have to test to be entered in the lottery $(n=316)$. Chi-square tests were conducted to measure significant differences between the two conditions distinguishing between permanent and non-permanent staff.

Main findings: No significant association was found between behaviour intention in the two settings for permanent workers' workplace HIV testing intention $\left(\chi^{2}=1.145, p=0.285\right.$, phi $=-0.097)$. However, a significant association with a small effect size was found for non-permanent workers $\left(\chi^{2}=8.04, p=0.005\right.$, phi $\left.=-0.279\right)$.

Practical/managerial implications: Results show that lotteries to encourage workplace HIV testing are very likely to help workers 'do the right thing' and unlikely to have a coercive effect if all staff attending HIV testing has participated in standardised HIV and AIDS workplace programme activities and is informed about the consequences of testing positive.

Contribution: A better understanding of how lotteries influence workplace HIV testing among workers of different work status and informed related recommendations.

\section{Introduction}

More than a billion people live on the African continent, of whom many millions are infected and affected by the HIV virus. The World of Work, which accommodates many HIV-positive employees, plays an important role in helping alleviate the negative consequences of the pandemic; for example, a recent systematic review showed that HIV-positive people who have a job are nearly $40 \%$ more likely to be adherent to their HIV treatment than those who are not working (ILO, 2013). Still, an urgent need for interventions to improve companies' workplace HIV testing rates has been identified (Arimoto, Seiro, Kudo \& Kazunari, 2013; Bhagwanjee, Petersen, Akintola \& George, 2008; SABCOHA, 2015).

Provision of incentives to increase HIV testing uptake may be a useful tool to encourage workplace HIV counselling and testing (HCT) (George \& Quinlan, 2009; Lee, Cui, Muessig, Thirumurthy \& Tucker, 2014; Mahajan, Colvin, Rudatsikira \& Ettl, 2007; Weihs \& Meyer-Weitz, 2014). In South Africa, the Automotive Industry Development Centre, Eastern Cape, together with the Deutsche Gesellschaft für Internationale Zusammenarbeit $\mathrm{GmbH}$ have been supporting the use of lottery incentives to encourage workplace HIV testing within the automotive manufacturing sector in the Nelson Mandela Bay Municipality (NMBM). Lotteries can encourage employees HIV 
testing behaviour and also help to improve HIV testing uptake necessary for companies to determine a reliable HIV prevalence rate for their workforce (Weihs \& Meyer-Weitz, 2014, in press). Human resource managers require these data for their companies' strategic human resource planning in order to 'ensure that the right numbers of the right kinds of people are available at the right times and in the right places to translate organisational plans into reality' (Rothwell \& Kazanaz, 2003, p. 2), as well as ensuring timely support and care to HIV-infected employees. Still, more research is necessary to clarify the theoretical underpinnings of lottery interventions (Lee et al., 2014; Weihs \& Meyer-Weitz, 2014, 2016) as there is a lack of empirical evidence on how lottery incentives may influence employees' workplace HCT behaviour. This may constitute a critical element towards trying to understand, predict and support employees' workplace HCT performance. Although lotteries used to encourage HIV testing in South Africa have been criticised to coerce people to participate in HIV testing (Cameron \& Van der Merwe, 2012; Office of the ANC Chief Whip, 2011), first studies done in South African companies show that lotteries influenced employees' HIV testing behaviour through positive social pressure (Weihs \& Meyer-Weitz, 2014, in press). However, the two mentioned studies could not exclude the possibility that some employees might have participated in workplace HCT just because they wanted to win the lottery. Interviewees stated that for some employees, the possibility of winning the lottery appeared to be the only motivating factor to participate in workplace HIV testing regardless of all HIV and AIDS workplace programme (WPP) activities done to sensitise employees to the importance of knowing your HIV status (Weihs \& Meyer-Weitz, 2014). Past experience of receiving rewards and the possibility of being rewarded in the future are known to motivate people (Kahneman \& Tversky, 1979; Loewenstein, Weber, Hsee \& Welch, 2001). Lotteries have been found to particularly improve participation in health behaviour activities among staff with lower income (Haisley, Volpp, Pellathy \& Loewenstein, 2012).

\section{Purpose}

This research formed part of a larger study examining the influence of lotteries on workers' workplace HIV testing behaviour within the automotive industry in South Africa. Lotteries' positive and also negative influences on workers' HIV testing behaviour need to be understood to avoid undue coercion of employees. More studies on incentives are needed that measure complex constructs such as coercion (Marteau, Ashcroft \& Oliver, 2009). Because of the highly different employment nature of permanent versus non-permanent workers with all its implications pertaining to their legal status and differences in levels of wages, access to HIV and AIDS WPP activities, social security and education levels, the decision was made in this study to distinguish lotteries' influence on permanent and non-permanent staff. Permanent staff is of central importance in companies' long-term strategic human resource planning while non-permanent staff, a significant group, is estimated to make up about $7 \%$ of
South Africa's total labour force (The World Bank, 2013). To allow better understanding of lotteries' influence on companies' staff, this study investigated whether permanent and non-permanent workers intended to test for HIV only to win a prize when lotteries were used. The study contributed towards a growing body of knowledge about the use of incentives in encouraging workplace health-screening behaviours, in particular, the use of lottery incentives to improve workplace HCT uptake. Managers, health practitioners and even funding agencies have an interest in finding ways to encourage workplace HIV testing in ways that do not result in undue coercion. The results of this study are argued to inform recommendations on the use of lotteries in encouraging workplace HIV testing.

\section{Literature review}

The importance of determining workplace HIV prevalence

South Africa has the world's largest HIV and AIDS epidemic (UNAIDS, 2014). An estimated $90 \%$ of HIV-positive people are in the economically active age group (SABCOHA, 2015; Setswe, 2009). Yet, recent studies show that in 2012 only $44.8 \%$ of the estimated 6.4 million HIV-positive people living in South Africa knew their HIV status (Shisana, 2013); therefore, many may not seek timely treatment. To address the epidemic, the South African National Strategic Plan on HIV, STIs and TB, 2012-2016 (SANAC, 2012), and the Code of Good Practice on HIV and AIDS and the World of Work (Department of Labour, 2012) foresee that workplaces should address HIV, which would include the promotion of HCT that is considered to be one of the most effective and efficient instruments in HIV prevention and access to care in Africa (Corbett et al., 2006). HIV management in the workplace is becoming a priority for companies operating in countries with a high HIV prevalence (Arimoto et al., 2013; George \& Quinlan, 2009) as HIV and AIDS are eroding corporate investments and companies are losing trained staff because of AIDS (Arimoto et al., 2013; George, Surgey \& Gow, 2014). In the context of wide access to antiretroviral treatment (ART), HIV-positive workers unaware of their status may not receive timely support and treatment that will prevent illhealth and an untimely death, detrimental to both their families and companies. Consequently, many companies in South Africa have introduced HIV and AIDS WPP (Arimoto et al., 2013; Ellis \& Terwin, 2005). These WPP interventions cover, for example, HIV and AIDS policies, HIV prevention, treatment and care education, provision of condoms, workplace HCT, ART or medical referral for treatment of employees (Mahajan et al., 2007). To ensure quality and standardisation of such WPP, the South African Bureau of Standards developed the SANS 16001:2013, a national standard for a wellness and disease management system including HIV and TB (Gansan, 2013). One of the key issues of these HIV and AIDS WPP is the focus on determining a reliable HIV prevalence for the company's staff through workplace HCT. High workplace HCT participation allows defining a reliable company HIV prevalence rate, which in turn is a prerequisite for efficient and effective HIV and AIDS 
management (UNAIDS, 2002). This has also been acknowledged by the SANS 16001:2013 wellness and disease management system that aims to provide organisations with solid data and statistics on the health determinants and burden of disease within their workplaces necessary for proper strategic human resource planning (Gansan, 2013). Unfortunately, relatively low HIV testing uptake rates are reported by South Africa's companies (Connelly \& Rosen, 2006; George, 2006; George \& Quinlan, 2009; SABCOHA, 2015). Offering incentives might be a useful tool to encourage workplace HCT (George \& Quinlan, 2009; Lee et al., 2014; Mahajan et al., 2007; Weihs \& Meyer-Weitz, 2014).

\section{Lotteries to encourage HIV testing, a contentious subject in South Africa}

From a cultural perspective, competitions such as lotteries are extremely popular among South Africans and are especially present in people's daily life (Van Wyk, 2012). In her study, Van Wyk (2012) found that although almost 70\% of her study's interviewees reported never winning anything in the lottery, $80 \%$ of them kept on 'taking a chance'.

Lottery competitions have already been used for mass HIV testing in South Africa. For instance, the South African 'Right to Know' HIV testing competition tested more than 50000 people in 2009 (Keeton, 2009). Supporters of the use of lotteries for encouraging HIV testing claim that lotteries help people to make the 'right choice' and are not coercive. Neville Koopowitz, CEO of Discovery Health that supported the 'Right to Know' competition, said that his organisation wanted to apply its 'model of giving people incentives to participate in healthy behaviours ... to our country's most pressing and important health issue' (Keeton, 2009, p. 2). Sunday Times editor Mondli Makhanya described how lotteries made it exciting to test: 'By offering an incentive, we believe that the Right to Know campaign has contributed to making it hip to test' (Keeton, 2009, p. 2). New Start's technical adviser, Scott Billy, said:

I think it's a great idea. If you test and win the prize, you've won twice. You've won some money and you've won the opportunity to take control of your health, your life and your family's future by learning your HIV status. And if you don't win the prize, you've still won because you got yourself tested. (Keeton, 2009, p. 2)

There are many examples in South Africa where lotteries are claimed to have increased HIV testing rates and thus promoted efficiency: a little increase in expenditures for lotteries nevertheless created a large health benefit. In November 2011, the Western Cape Government implemented a pilot lottery to encourage people in communities to get tested for HIV. Preliminary indications show that the incentive scheme significantly increased the number of people tested (Mbhele, 2011). When the National Department of Health launched its HIV testing campaign 'First Things First' among tertiary institutions in the country, prizes such as a car, laptop computer and book vouchers were offered in the lottery to attract students to test. As an incentive to participate, firstyear students could enter a lucky draw at each campus.
Approximately $97 \%$ of students counselled and tested for HIV (Cameron \& Van der Merwe, 2012). The 'First Things First' campaign was overall described as a great success and was awarded by the African Network for Strategic Communication in December 2011. The non-governmental organisation Bulungula Incubator managed to triple the HIV testing uptake in four Eastern Cape villages by using lotteries to encourage villagers to check their status (Malan, 2013). In various discussions held with senior staff of the automotive industry in the Nelson Mandela Bay, South Africa, one of the authors learned that they were convinced that lotteries increased workplace HCT rates, that staff highly appreciated lotteries and that it created a positive atmosphere around workplace HCT. In an interview, Sean Jelly, CEO of a South African company specialising in providing HIV and AIDS medical support to corporate employers, reported that lotteries greatly increased workplace HCT uptake among their clients (George \& Quinlan, 2009).

While Rebecca Hodes, Director of Policy for the Treatment Action Campaign welcomed initiatives to promote HIV testing, some of the Treatment Action Campaign leaders and members were critical of lotteries and said that 'it is a great enough incentive to know your status and to access antiretrovirals if you need them' (Keeton, 2009, p. 2). Lotteries are described to be coercive as they put undue pressure on people to participate in HIV testing (Cameron \& Van der Merwe, 2012), especially on a person in desperate need for extra financial income. The Office of the ANC Chief Whip argued with regard to the 2011 Western Cape's Government lottery that the HIV and AIDS testing lottery down played the gravity of HIV and AIDS and that it generated the impression that HIV and AIDS concern only the poor, who are easily tempted by prizes (Office of the ANC Chief Whip, 2011). A frequent criticism is that lotteries to encourage HIV testing are a poor use of public resources that should rather be used for more urgent needs: 'The battle against HIV/ AIDS must not be a game where people's participation is motivated by winning the jackpot', and that the money might be better spent if handed over to the National AIDS Council and the Department of Health (Office of the ANC Chief Whip, 2011, p. 1). Lotteries are accused of being paternalistic as they undermine individuals' autonomy. Lotteries used in the 2011 Western Cape's Government lottery were described to undermine the importance of HIV and AIDS education that ensures understanding of HIV testing, counselling and the advantages of knowing one's status (Office of the ANC Chief Whip, 2011).

In conclusion, many claims for and against the use of lotteries to influence workplace HCT in South Africa exist, but very little scientific evidence about their influence on employees' workplace HIV testing behaviour has been published.

\section{Findings about lottery incentives to encourage workplace HIV counselling and testing}

The quantitative results of a study done in South African automotive companies in which lotteries were used to encourage workplace HCT showed that the announcement 
of lotteries significantly increased employees' workplace HCT behaviour intention and perceptions of support by the company, colleagues and family to participate in HIV testing. The results reflected employees' strong conviction that such a collective approach to workplace HCT would be successful. The lotteries helped to address various existing HCT barriers at a 'social-cultural-collective' level rather than at an individual level (Weihs \& Meyer-Weitz, in press). Furthermore, a qualitative study done in the same companies after the HIV testing to explore participants' experiences of the lottery and all aspects in this regard showed that in the 2 weeks prior to the HIV screening event, lotteries brought excitement to the workplace and enhanced shop-floor workers' personal interest in HIV testing (Weihs \& MeyerWeitz, 2014). This enabled social interactions and collective support among the staff with regard to participating in HIV testing and helped in mitigating HIV stigma. Lotteries were described as being a supportive and innovative company initiative. Employees expressed social support and encouragement for testing but did not experience this as coercive (Weihs \& Meyer-Weitz, 2014). A qualitative research study done among students who participated in the South African 'First Things First' campaign, showed similar findings. Most of the participants supported the lottery. Students' reported that the reasons for getting HIV tested were the excitement created by the campaign and friends encouraging them. Although many participants were encouraged by the prospect of winning a prize, no student reported feelings of coercion. The students reported that the decision to participate in HIV testing was based on 'their own best interests' (Cameron \& Van der Merwe, 2012).

Against the above background, this research posed the following question: How do lottery incentives influence permanent and non-permanent workers' workplace HIV testing behaviour intention, when lottery entry is conditional on HIV testing (setting 1) compared to when HIV testing is not conditional for entry into the lottery (setting 2)? If workers' workplace HCT behaviour intention in setting 1 was not found to be significantly higher than that in setting 2 , this would suggest that workers' intention to participate in workplace HIV testing was not significantly influenced by the prizes of the lottery.

\section{Method}

\section{Research approach}

This research forms part of a larger study examining the influence of lottery incentives on workers' workplace HCT behaviour. For more details about the methodology and particularly the measuring instruments, refer to Weihs and Meyer-Weitz (in press). A quantitative approach was followed. For this study, a post-test only, quasi-experimental study design was used in two different settings as described below. The workplace poses major challenges for impact assessments and limits the design of these studies.

\section{Participants}

The data for setting 1 were collected among shopfloor workers (permanent and non-permanent workers) in two independent automotive component manufacturing companies of the NMBM in November and December 2010. Similarly, the data for setting 2 were collected among shopfloor workers in two other independent automotive component manufacturing companies of the NMBM in July and November 2012. Participating companies had never offered incentives in the past to encourage workers to test for HIV in the workplace. None of the companies offered ART to their employees. Workers in all companies had been involved in a minimum of 6 months of HIV and AIDS WPP activities of similar standard. These comprised the implementation of HIV and AIDS policies and education activities directed at HIV prevention, treatment and care. All workers were also informed that a wellness event would soon be held on the premises of the company where four health-screening tests would be offered for free, that is, hypertension, blood sugar level, body mass index and HIV.

The study population included all permanent and nonpermanent shop-floor workers working in two different shifts, one shift receiving the experimental intervention, the other shift being the control group. In all companies, the two shifts were set up by production managers unaware of the research study when planning the shifts. The sample size of setting 1 was 203 workers, of whom 198 completed the questionnaires (control group [ $N=88]$ and experimental group [ $N=110]$, response rate was $97.5 \%$ ). The sample size of setting 2 was 356 workers, of whom 316 completed valid questionnaires (control group [ $N=147]$ and experimental group $[N=169]$, the response rate was $88.8 \%$ ).

\section{Measuring instruments}

For the larger study, a questionnaire was compiled in accordance to the Theory of Planned Behaviour (Ajzen, 1991) to measure predictors of workplace HCT behaviour intention for use in both settings. In addition, various socio-demographic information were sought, that is age, gender, marital status, highest education reached and employment status. However, for this research only data that measured workplace HCT behaviour intention and socio-demographics were used to answer the research question. Intention to participate in workplace HCT (BIntention) was investigated with the statement 'If the company would organise its on-site Wellness Day tomorrow, I would go testing for HIV tomorrow'. BIntention was assessed using a four-point Likert scale.

\section{Design}

A post-test only, quasi-experimental study design was used. A structured, self-administrated questionnaire in English was administered to the control and experimental groups in both settings. English was the official language used in the workplaces and the large majority of workers had national senior certificates. The experimental intervention was a leaflet informing shop-floor workers about data and venue of the wellness event and the conditions to be entered into the lottery (shopping vouchers worth R2000 [first prize], R500 [second prize], and 10 extra R100 prizes). In setting 1, the 
experimental intervention informed that while four healthscreening tests were offered, that is, hypertension, blood sugar level, body mass index and HIV, workers had to test for HIV to be entered into the lottery. In setting 2, the experimental intervention informed workers that in the context of the same four health-screening tests, they had to participate in three tests out of the four offered, to be entered into the lottery; so it was made clear that they did not necessarily have to participate in HIV testing to be entered in the lottery. The first prize was close to half a month of a worker's normal wage.

Peer educators supported the data collection by explaining and clarifying questions and misunderstandings. They were not informed about the experiment but were told that the survey was done to improve the HIV and AIDS WPP. The data were captured considering quality assurance for completeness and consistency.

Ethical approval for the study was obtained from the University of KwaZulu-Natal Ethics Committee (reference number HSS/1263/010).

\section{Analysis}

The study data were analysed using SPSS 22 software. Frequencies were calculated and the central tendencies of the data investigated. Chi-square tests were used to compare demographics of setting 1 with demographics of setting 2, distinguishing between permanent and non-permanent workers. For better distribution, BIntention was re-coded into a dichotomous variable because of a negatively skewed response rate. To determine whether workers' intention to test for HIV was solely based on a chance to win a lottery prize, chi-square tests were used to measure the difference in behaviour intention between settings 1 and 2 for the control and experimental groups, and distinguishing between permanent and non-permanent staff.

\section{Results}

The demographic characteristics of the permanent workers in ContGroup setting 1 and setting 2 and ExpGroup setting 1 and setting 2 are shown in Table 1. Chi-square for independence tests indicated no significant differences in terms of the proportions of age, gender, marital status and qualifications in the ContGroup setting 1, as compared to ContGroup setting 2 and ExpGroup setting 1 as compared to the ExpGroup setting 2. Thus, ContGroup setting 1 and ContGroup setting 2 were considered as comparable. ExpGroup setting 1 and ExpGroup setting 2 were also considered as comparable.

Similar to the above discussion, the demographic characteristics of the non-permanent workers in ContGroup setting 1, and setting 2 and ExpGroup setting 1 and setting 2 are shown in Table 2. Chi-square for independence tests indicated no significant differences in terms of the proportions of age, gender, marital status and qualifications in the ContGroup setting 1, as compared to ContGroup setting 2 and ExpGroup setting 1 as compared to the ExpGroup setting 2. Thus, the groups were considered comparable.

\section{Behaviour intention across settings and groups \\ Permanent workers}

A chi-square test for independence (with Yates Continuity Correction) indicated no significant difference between the control groups of permanent workers in both settings (not depicted in a table) for workplace HCT behaviour intention $\left(\chi^{2}=0.059, p=0.808\right.$, phi $\left.=0.037\right)$.

As depicted in Table 3, a chi-square test for independence (with Yates Continuity Correction) indicated no significant difference for workplace HCT behaviour intention between setting 1 and setting 2 for the experimental group of permanent workers $\left(\chi^{2}=1.145, p=0.285\right.$, phi $\left.=-0.097\right)$.

\section{Non-permanent workers}

A chi-square test for independence (with Yates Continuity Correction) indicated no significant difference between the control groups of non-permanent workers in both settings (not depicted in a table) for workplace HCT behaviour intention $\left(\chi^{2}=0.231, p=0.631\right.$, phi $\left.=-0.075\right)$.

\begin{tabular}{|c|c|c|c|c|c|c|c|c|c|c|}
\hline \multirow[t]{2}{*}{$\begin{array}{l}\text { Permanent workers' demographic } \\
\text { characteristics }\end{array}$} & \multicolumn{2}{|c|}{$\begin{array}{l}\text { Setting } 1 \text { ContGroup } \\
(n=59)\end{array}$} & \multicolumn{2}{|c|}{$\begin{array}{l}\text { Setting } 2 \text { ContGroup } \\
(n=80)\end{array}$} & \multirow[t]{2}{*}{$p(N=139)$} & \multicolumn{2}{|c|}{$\begin{array}{l}\text { Setting } 1 \text { ExpGroup } \\
\qquad(n=77)\end{array}$} & \multicolumn{2}{|c|}{$\begin{array}{l}\text { Setting } 2 \text { ExpGroup } \\
\qquad(n=83)\end{array}$} & \multirow[t]{2}{*}{$p(N=160)$} \\
\hline & $n$ & $\%$ & $n$ & $\%$ & & $n$ & $\%$ & $n$ & $\%$ & \\
\hline Age in years & - & - & - & - & 0.682 & - & - & - & - & 0.281 \\
\hline$\leq 29$ & 15 & 25.4 & 14 & 17.5 & - & 24 & 31.2 & 15 & 18.1 & - \\
\hline $30-34$ & 12 & 20.3 & 18 & 22.5 & - & 16 & 20.8 & 21 & 25.3 & - \\
\hline $35-40$ & 17 & 28.8 & 28 & 35.0 & - & 21 & 27.3 & 25 & 30.1 & - \\
\hline$\geq 41$ & 15 & 25.4 & 20 & 25.0 & - & 16 & 20.8 & 22 & 26.5 & - \\
\hline Gender & - & - & - & - & 0.915 & - & - & - & - & 0.992 \\
\hline Male & 34 & 57.6 & 48 & 60.0 & - & 50 & 64.9 & 55 & 66.3 & - \\
\hline Female & 25 & 42.4 & 32 & 40.0 & - & 27 & 35.1 & 28 & 33.7 & - \\
\hline Marital status & - & - & - & - & 0.053 & - & - & - & - & 0.206 \\
\hline Single, divorced and widower & 35 & 59.3 & 33 & 41.3 & - & 43 & 55.8 & 37 & 44.6 & - \\
\hline Married & 24 & 40.7 & 47 & 58.8 & - & 34 & 44.2 & 46 & 55.4 & - \\
\hline Highest education reached & - & - & - & - & 0.091 & - & - & - & - & 0.183 \\
\hline High school & 16 & 27.1 & 20 & 25.0 & - & 21 & 27.3 & 34 & 41.0 & - \\
\hline Matric & 26 & 44.1 & 48 & 60.0 & - & 38 & 49.4 & 32 & 38.6 & - \\
\hline College and university & 17 & 28.8 & 12 & 15.0 & - & 18 & 23.4 & 17 & 20.5 & - \\
\hline
\end{tabular}


TABLE 2: Summary socio-demographics for non-permanent workers.

\begin{tabular}{|c|c|c|c|c|c|c|c|c|c|c|}
\hline \multirow[t]{2}{*}{$\begin{array}{l}\text { Non-permanent workers' demographic } \\
\text { characteristics }\end{array}$} & \multicolumn{2}{|c|}{$\begin{array}{l}\text { Setting } 1 \text { ContGroup } \\
(n=29)\end{array}$} & \multicolumn{2}{|c|}{$\begin{array}{l}\text { Setting } 2 \text { ContGroup } \\
(n=67)\end{array}$} & \multirow[t]{2}{*}{$p(N=96)$} & \multicolumn{2}{|c|}{$\begin{array}{l}\text { Setting } 1 \text { ExpGroup } \\
\quad(n=33)\end{array}$} & \multicolumn{2}{|c|}{$\begin{array}{l}\text { Setting } 2 \text { ExpGroup } \\
\quad(n=86)\end{array}$} & \multirow[t]{2}{*}{$p(N=119)$} \\
\hline & $n$ & $\%$ & $n$ & $\%$ & & $n$ & $\%$ & $n$ & $\%$ & \\
\hline Age in years & - & - & - & - & 0.095 & - & - & - & - & 0.446 \\
\hline$\leq 29$ & 13 & 44.8 & 25 & 37.3 & - & 12 & 36.4 & 29 & 33.7 & - \\
\hline $30-34$ & 9 & 31.0 & 10 & 14.9 & - & 6 & 18.2 & 22 & 25.6 & - \\
\hline $35-40$ & 4 & 13.8 & 12 & 17.9 & - & 5 & 15.2 & 19 & 22.1 & - \\
\hline$\geq 41$ & 3 & 10.4 & 20 & 29.9 & - & 10 & 30.3 & 16 & 18.6 & - \\
\hline Gender & - & - & - & - & 1.000 & - & - & - & - & 0.389 \\
\hline Male & 22 & 75.9 & 51 & 76.1 & - & 20 & 60.6 & 61 & 70.9 & - \\
\hline Female & 7 & 24.1 & 16 & 23.9 & - & 13 & 39.4 & 25 & 29.1 & - \\
\hline Marital status & - & - & - & - & 0.899 & - & - & - & - & 0.199 \\
\hline Single, divorced and widower & 18 & 62.1 & 39 & 58.2 & - & 23 & 69.7 & 47 & 54.7 & - \\
\hline Married & 11 & 28.2 & 28 & 41.8 & - & 10 & 30.3 & 39 & 45.3 & - \\
\hline Highest education reached & - & - & - & - & 0.114 & - & - & - & - & 0.501 \\
\hline Matric & 15 & 51.7 & 36 & 53.7 & - & 19 & 57.6 & 50 & 58.1 & - \\
\hline College and university & 3 & 10.3 & 7 & 10.4 & - & 3 & 9.1 & 14 & 16.3 & - \\
\hline
\end{tabular}

TABLE 3: Relationship between BIntention and settings 1 and 2 for permanent workers.

\begin{tabular}{|c|c|c|c|c|c|c|c|}
\hline \multirow[t]{2}{*}{ Experimental group permanent workers } & \multicolumn{2}{|c|}{ Setting 1 ExpGroup $(n=77)$} & \multicolumn{2}{|c|}{ Setting 2 ExpGroup $(n=83)$} & \multirow[t]{2}{*}{$p(N=160)$} & \multirow[t]{2}{*}{ phi } & \multirow[t]{2}{*}{ Effect size } \\
\hline & $n$ & $\%$ & $n$ & $\%$ & & & \\
\hline BIntention & - & - & - & - & 0.285 & -0.097 & Small \\
\hline Some BIntention & 38 & 49.4 & 49 & 59.0 & - & - & - \\
\hline Strong BIntention & 39 & 50.6 & 34 & 41.0 & - & - & - \\
\hline
\end{tabular}

TABLE 4: Relationship between BIntention and settings 1 and 2 for non-permanent workers.

\begin{tabular}{|c|c|c|c|c|c|c|c|}
\hline \multirow{2}{*}{$\begin{array}{l}\text { Experimental Group } \\
\text { Non-Permanent Workers }\end{array}$} & \multicolumn{2}{|c|}{ Setting 1 ExpGroup $(n=33)$} & \multicolumn{2}{|c|}{ Setting 2 ExpGroup ( $n=86)$} & \multirow[t]{2}{*}{$p(N=119)$} & \multirow[t]{2}{*}{ phi $(N=119)$} & \multirow[t]{2}{*}{ Effect size } \\
\hline & $n$ & $\%$ & $n$ & $\%$ & & & \\
\hline BIntention & - & - & - & - & 0.005 & -0.279 & Small \\
\hline Some BIntention & 13 & 39.4 & 60 & 69.8 & - & - & - \\
\hline Strong BIntention & 20 & 60.6 & 26 & 30.2 & - & - & - \\
\hline
\end{tabular}

Table 4 shows that for the ExpGroup among non-permanent workers, a significant difference was measured between setting 1 and setting $2\left(\chi^{2}=8.04, p=0.005\right)$. The effect size (phi $=-0.279)$ using Cohen's (1988) criteria, was small.

\section{Discussion}

\section{Outline of results}

This study compared the influence of lottery incentives on workplace HCT behaviour intention in two settings: (1) when entry into the lottery was conditional on HIV testing and (2) when HIV testing was not conditional for entry into the lottery. The findings also shed light on whether the respondents intended to test for HIV only because of the chance to win a prize when lotteries were used to encourage workplace HCT.

In terms of the control groups' workplace HCT behaviour intentions between settings 1 and 2 for permanent and nonpermanent workers, no significant differences emerged. This was expected as there was no significant difference in the socio-demographics, and both groups were exposed to very similar HIV and AIDS WPP activities. In addition, to ensure constant quantity, quality and costs of production, production managers tend to put together fairly similar groups of workers for the shifts in their companies.
No significant difference was found for workplace HCT behaviour intention between setting 1 and setting 2 for the experimental groups of permanent workers. Here, the same proportion of workers indicated a strong behavioural intention to participate in workplace HCT irrespective of whether they had to participate in workplace HCT to be entered into the lottery or not. This result indicates that the announcement of lotteries did not pressurise permanent workers to choose between HIV testing and having the chance to access extra financial income or not testing and being excluded from a chance of extra income. This result and the findings of Weihs and Meyer-Weitz (2014, 2016) supported the conclusion that lotteries were highly likely to have played a catalyst role, that is, fostered excitement, positive feelings of encouragement and support for workplace HIV testing rather than being coercive. This finding corroborates with that of Cameron and Van der Merwe (2012) in their study among students where it was reported that although many participants were encouraged by the prospect of winning a prize, no student reported feelings of coercion.

The non-permanent workers represented nearly $42 \%$ of the study population. This is a very high figure knowing that temporary workers make up an estimated 7\% of South Africa's labour force as mentioned above 
(The World Bank, 2013). A significant difference for workplace HCT behaviour intention was found between setting 1 and setting 2 for the experimental group of non-permanent workers. However, according to Cohen's criteria (1988), the effect size was small and of limited practical value. Caution should be taken when interpreting this result as the sample size was small. When non-permanent workers did not have to participate in workplace HCT to be entered in the lottery, proportionally fewer workers were motivated to participate in workplace HCT. These results indicate that when lotteries were announced, non-permanent workers' HIV testing intention was slightly higher in setting 1 than in setting 2, thus suggesting that some non-permanent workers mainly intended to participate in HIV testing because they wanted to be eligible to win a lottery prize.

Lotteries have been previously found to improve participation in health behaviours, particularly among staff with lower levels of income (Haisley et al., 2012). A recent study by Dickinson (2015) among post office workers revealed that, although working alongside permanent workers and doing the same work, non-permanent workers had very different terms and conditions of employment and earned just a quarter of what permanent workers were earning. The chances that non-permanent workers contribute to pension funds or medical aid, are smaller (The World Bank, 2013). Furthermore, non-permanent workers face higher insecurity of employment as their employment can suddenly be ended at the demand of the client (Bamu \& Godfrey, 2009). Although this study did not collect data about the income and other benefits of study participants, the above-mentioned literature findings could be an explanation for non-permanent workers' workplace HIV testing intention being slightly positively influenced by their interest in winning a lottery prize. For this more vulnerable sample of workers, lotteries might have created an irresistible offer pushing them to choose testing to have a chance of accessing extra financial income over not testing and being excluded from a chance of extra income. However, a qualitative study done after the HIV testing event in setting 1, companies described how lotteries in the 2 weeks before HIV testing took place in the companies, brought excitement to the workplace and enhanced shop-floor workers' personal interest in HIV testing (Weihs \& MeyerWeitz, 2014). This enabled social interactions and collective support among the staff with regard to participating in HIV testing and helped mitigating HIV stigma. The study interviewees who consisted of permanent and nonpermanent staff described lotteries as being a supportive and innovative company initiative. Still, as the above quantitative results show that non-permanent employees' HIV testing behaviour intention was significantly influenced by the prizes, it cannot be excluded that some non-permanent workers only tested to win a prize and in this way were slightly more coerced to test.

\section{Limitations and recommendations}

The study only measured the influence of specific lottery prizes on employees' behaviour intention. It did not include a follow-up to clarify whether workers translated their intentions into practice. Furthermore, the influence of other types and values of lottery prizes on employees' behaviour needs to be clarified. Findings of this study are based on relatively small samples in companies that had implemented an HIV and AIDS WPP of a specific standard. Further studies with bigger samples and in different settings are necessary to generalise the results.

Recommendations were developed in addition to those proposed by Weihs and Meyer-Weitz (2014, in press): When making use of lotteries to encourage workers' workplace HIV testing, it is important that all workers presenting for HIV testing benefitted from HIV and AIDS WPP and it is made sure that they are informed about all implications of testing positive, their rights as well as how to access treatment and care. To assure this, contracts signed with labour brokers should foresee that all non-permanent staff to be placed should benefit from HIV and AIDS WPP. To assure quality, HIV and AIDS WPPs should be based on widely acknowledged standards and evaluated regularly as per the Code of Good Practice on HIV and AIDS and the World of Work (Department of Labour, 2012) and/or SANS 16001:2013 (Gansan, 2013). This ethical practice should be integral to HIV management as part of strategic human resource planning.

\section{Conclusion}

The results of this study allowed comparing the influence of lottery incentives on workplace HCT behaviour intention in two settings: (1) when entry into the lottery was conditional on HIV testing and (2) when HIV testing was not conditional for entry into the lottery. In the case of permanent workers, no significant association was found between the behaviour intentions to test in the two settings. For these workers, testing intention was not significantly influenced by their interest in winning a lottery prize. However, for the nonpermanent workers a significant, yet small difference was found. When lotteries were announced, non-permanent employees' HCT behaviour intention was slightly higher in setting 1 than in setting 2 , suggesting that some were likely to have participated in HIV testing for entry into the lottery in the hope of winning a prize. This could be linked to their often poorer employment conditions than permanent employees. However, the effect size was small. Caution is also needed when interpreting the result because of the small sample size. These results and the findings of Weihs and Meyer-Weitz (2014, in press) strongly suggest that the use of lotteries to encourage workplace HIV testing are highly likely to help workers 'do the right thing' and is unlikely to be unduly coercive. Ethical practice in HIV management also demands that before HIV testing, all workers participate in standardised HIV and AIDS WPP activities and are well informed about the consequences, support and treatment available when testing HIV positive.

\section{Acknowledgements}

We thank the companies and workers who participated in the study. We would also like to thank the Human Sciences 
Research Council, the Automotive Industry Development Centre Eastern Cape and the Deutsche Gesellschaft für Internationale Zusammenarbeit $\mathrm{GmbH}$ for supporting the research.

\section{Competing interests}

The authors declare that they have no financial or personal relationships which may have inappropriately influenced them in writing this article.

\section{Authors' contributions}

M.W. and A.M-W. conceived and designed the experiments. M.W. performed the experiments. M.W. and A.M-W. analysed the data and wrote the manuscript.

\section{References}

Ajzen, I. (1991). The theory of planned behavior. Organizational Behavior and Human Decision Processes, 50(2), 179-211. http://doi.org/10.1016/07495978(91)90020-T

Arimoto, Y., Seiro, I., Kudo, Y., \& Kazunari, T. (2013). Stigma, social relationship and HIV testing in the workplace: Evidence from South Africa (CEI Working Paper Series No. 2012-06). Center for Economic Institutions, Institute of Economic Research, Hitotsubashi University. Retrieved June 07, 2015 from http://econpapers.repec. org/paper/hithitcei/2012-06.htm

Bamu, P., \& Godfrey, S. (2009). Exploring labour broking in the South African construction industry. Braamfontein, South Africa: Building \& Wood Workers' International. Retrieved May 10, 2015, from http://www.Irs.org.za/docs/BWI_ Labour\%20Broking\%20Booklet.pdf

Bhagwanjee, A., Petersen, I., Akintola, O., \& George, G. (2008). Bridging the gap between VCT and HIV/AIDS treatment uptake: Perspectives from a mining-secto workplace in South Africa. African Journal of AIDS Research, 7(3), 271-279.

Cameron, D.A., \& Van der Merwe, H. (2012). Are students being coerced into testing for HIV? Ethical considerations related to offering incentives for HIV counselling and testing at tertiary institutions in South Africa. South African Journal of Bioethics and Law, 5(2), 95-97. http://doi.org/10.7196/SAJBL.197

Cohen, J. (1988). Statistical power analysis for the behavioral sciences. (2nd edn.) Hillsdale, NJ: Lawrence Erlbaum. Retrieved August 05, 2015, from http://books. google.com/books?id=TION2IRAO9oC

Connelly, P., \& Rosen, S. (2006). Treatment for HIV/AIDS at South Africa's largest employers: Myth and reality. South African Medical Journal, 96(2), 128-133.

Corbett, E.L., Dauya, E., Matambo, R., Cheung, Y.B., Makamure, B., Bassett, M.T., et al (2006). Uptake of workplace HIV counselling and testing: A cluster-randomised trial in Zimbabwe. PLoS Medicine, 3(7), e238.

Department of Labour. (2012). South African code of good practice on HIV and AIDS and the World of Work in Employment Equity Act, No. 55 of 1998. Republic of South Africa: Department of Labour. Retrieved May 05, 2015, from http://www. labour.gov.za/DOL/downloads/legislation/acts/employment-equity/ hivaidstechnicalguide.pdf

Dickinson, D. (2015). Contracting out of the constitution: Casual workers and the failure of South Africa's industrial relations framework. Retrieved May 15, 2015, from http://wiser.wits.ac.za/system/files/seminar/Dickinson2015.pdf

Ellis, L., \& Terwin, J. (2005). The impact of HIV\&AIDS on selected business sectors in South Africa, 2005. Stellenbosch: SABCOHA and Bureau for Economic Research. Retrieved May 05, 2015, from http://www.ber.ac.za/Themes/Content Themes/ BER 2.02011/Templates/contentgeneral.aspx/?pageidref $=1731$

Gansan, J. (2013, March). SANS 16001:2013 Wellness and Disease Management System (including HIV AND TB). Presentation, South African Bureau of Standards, SABS. Retrieved May 16, 2015, from https://www.sabs.co.za/docs\%5CJai\%20 GaBS. Retrieved May 16, 2015, from httf

George, G. (2006). Workplace ART programmes: Why do companies invest in them and are they working? African Journal of AIDS Research, 5(2), 179-188.

George, G., \& Quinlan, T. (2009). 'Health management' in the private sector in the context of HIV/AIDS: Progress and challenges faced by company programmes in South Africa. Sustainable Development, 17(1), 19-29.
George, G., Surgey, G., \& Gow, J. (2014). South Africa's private sector investment in training and its erosion as a result of HIV and AIDS. South African Journal of Economic and Management Sciences, 17(2), 109-123.

Haisley, E., Volpp, K.G., Pellathy, T., \& Loewenstein, G. (2012). The impact of alternative incentive schemes on completion of health risk assessments. American Journal of Health Promotion, 26(3), 184-188. http://doi.org/10.4278/ajhp.100729-ARB-257

ILO. (2013). The impact of employment on HIV treatment adherence. Geneva: International Labour Organisation. Retrieved May 05, 2015, from http://www.ilo. org/aids/Publications/WCMS_230625/lang--en/index.htm

Kahneman, D., \& Tversky, A. (1979). Prospect theory: An analysis of decision under risk. Econometrica, 47(2), 263-291. http://doi.org/10.2307/1914185

Keeton, C. (2009, August 18). Disagreement over whether prizes should be offered to those who want to learn whether they're negative or positive. Times Live. Retrieved May 05, 2015, from http://www.timeslive.co.za/specialreports/ hivaids/2009/08/18/50000-pass-our-hiv-testing

Lee, R., Cui, R.R., Muessig, K.E., Thirumurthy, H., \& Tucker, J.D. (2014). Incentivizing HIV/STI testing: A systematic review of the literature. AIDS and Behavior, 18(5), 905-912.

Loewenstein, G.F., Weber, E.U., Hsee, C.K., \& Welch, N. (2001). Risk as feelings. Psychological Bulletin, 127(2), 267-286. http://doi.org/10.1037/0033-2909.127. 2.267

Mahajan, A.P., Colvin, M., Rudatsikira, J.-B., \& Ettl, D. (2007). An overview of HIV/AIDS workplace policies and programmes in southern Africa. AIDS, 21(3), 31-39.

Malan, M. (2013, November 29). Villagers flock to take HIV tests. Retrieved May 05, 2015, from http://mg.co.za/article/2013-11-29-villagers-flock-to-take-hiv-tests/

Marteau, T.M., Ashcroft, R.E., \& Oliver, A. (2009). Using financial incentives to achieve healthy behaviour. British Medical Journal (clinical Research Ed.), 338, 983-985.

Mbhele, Z. (2011, December 14). Premier Zille conducts final prize draw of HIV testing campaign / Western Cape Government (14 December 2011). Retrieved May 05, 2015, from https://www.westerncape.gov.za/news/premier-zille-conducts-finalprize-draw-hiv-testing-campaign

Office of the ANC Chief Whip. (2011). Zille must scrap HIV-Testing Lottery (1 December 2011). Retrieved May 05, 2015, from http://www.anc.org.za/caucus/show. php?ID=2436

Rothwell, W.J., \& Kazanaz, H.C. (2003). Planning \& managing human resources: Strategic planning for personnel management. (2nd edn.). Human Resource Development Press, Inc. Retrieved May 11, 2015, from http://recruitusmc.org/ wp-content/uploads/2014/11/William-J.-Rothwell-H.-C.-Kazanas-Planning-andwp-content/uploads/2014/11/William-J.-Rothwell-H.-C.-Kazanas-
Managing-Human-Resources-Second-Edition-HRD-Press-2002.pdf

SABCOHA. (2015). HIV \& business overview. South African Business Coalition on Health and AIDS. Retrieved May 05, 2015, from http://www.sabcoha.org/hivbusiness-overview/

SANAC. (2012). The National Strategic Plan (NSP) 2012-2016. Johannesburg: South African National AIDS Council. Retrieved October 29, 2015, from http://sanac.org. za/resources/cat_view/2-nsp

Setswe, G.K.G. (2009). Best practice workplace HIV/AIDS programmes in South Africa: A review of case studies and lessons learned. African Journal of Primary Health Care \& Family Medicine, 1(1), 1-6. http://doi.org/10.4102/phcfm.v1i1.30

Shisana, O. (2013, June 20). HIV/AIDS in South Africa: At last the glass is half full. Retrieved May 05, 2015, from http://www.hsrc.ac.za/en/media-briefs/hiv-aidsstis-and-tb/plenary-session-3-20-june-2013-hiv-aids-in-south-africa-at-last-thestis-and-tb/plenary
glass-is-half-full

The World Bank. (2013). The World Development Report 2013. Washington, DC: The World Bank. Retrieved October 05, 2015, from http://econ.worldbank.org/ external/default $/ \mathrm{main}$ ?contentMDK=23044836\&theSitePK=8258025\&piPK=8258 412\&pagePK=8258258\&cid=EXT_FBWBPubs_P_EXT

UNAIDS. (2002). The private sector responds to the epidemic: Debswana - A global Benchmark. (Case Study, UNAIDS Best Practice Collection.). Geneva: Joint United Nations Programme on HIV\&AIDS. Retrieved May 05, 2015, from http://data. unaids.org/publications/irc-pub02/jc769-debswana_en.pdf

UNAIDS. (2014). Gap report. Geneva: Joint United Nations Programme on HIV\&AIDS. Retrieved May 05, 2015, from http://www.unaids.org/en/resources/ campaigns/2014/2014gapreport/gapreport

Van Wyk, I. (2012). 'Tata ma chance': On contingency and the lottery in post-apartheid South Africa. The Journal of the International African Institute, 82(1), 41-68.

Weihs, M., \& Meyer-Weitz, A. (2014). A lottery incentive system to facilitate dialogue and social support for workplace HIV counselling and testing: A qualitative inquiry. Journal of Social Aspects of HIV/AIDS, 11(1), 116-125. http://doi.org/10.1080/17 290376.2014.937739

Weihs, M., \& Meyer-Weitz, A. (in press). Examining how incentives influence workplace HIV testing using the theory of planned behaviour. African Journal for AIDS Research, manuscript under review. 